05

\title{
МСМ исследование влияния механических напряжений на магнитное состояние частиц $\mathrm{Ni}$
}

\author{
(C) О.Л. Ермолаева, Н.С. Гусев, Е.В. Скороходов, В.В. Рогов, О.Г. Удалов \\ Институт фозиики микроструктур РАН, \\ Нижегородская область, Афонино, Россия \\ E-mail: ermolaeva@ipmras.ru
}

Поступила в Редакцию 15 апреля 2019 г.

В окончательной редакции 22 апреля 2019 г.

Принята к публикации 24 апреля 2019 г.

\begin{abstract}
Исследовано влияние деформаций на ферромагнитные частицы. Изготовлены массивы Ni микрочастиц различной формы на стеклянной подложке. Исследовано магнитное состояние изготовленных частиц с помощью магнитно-силового микроскопа в зависимости от степени изгиба стеклянной подложки. Основное состояние неизогнутых частиц является вихревым. Изгиб подложки приводит к переходу из вихревого состояния в квазиоднородное.
\end{abstract}

Ключевые слова: ферромагнитные наночастицы, магнитно-силовая микроскопия, стрейнтроника , механические деформации, ферромагнетизм.

DOI: $10.21883 /$ FTT.2019.09.48100.03N

\section{1. Введение}

В настоящее время управление магнитными микрообъектами объектами, такими как магнитные частицы, доменные стенки и скирмионы, осуществляется либо однородным внешним магнитными полем либо с помощью пропускания значительных электрических (спинполяризованных) токов через систему. Эти подходы не позволяют осуществлять энергетически эффективное локальное управление доменными стенками и скирмионами (КПД порядка 0.0005\%) [1]. В конечном итоге это препятствует созданию микроэлектронных устройств на основе магнитных наносистем. Поэтому, многие научные группы в настоящее время исследуют фундаментально новые механизмы взаимодействия между электрическими и магнитными степенями свободы (магнитоэлектрический эффект). Особое внимание уделяется механизмам, в которых управление магнитными объектами осуществляется не электрическими токами, а электрическими полями $[2,3,4]$. Одним из возможных механизмов магнитоэлектрического эффекта является стрикционный магнитоэлектрический эффект в гибридных структурах ферромагнетик/сегнетоэлектрик. В рамках этого механизма деформации, вызываемые электрическим полем в сегнетоэлектрике, передаются в ферромагнетик и вызывают изменение магнитной анизотропии за счет магнитострикционного эффекта. Данный механизм изучен в пленочных структурах. Начаты также исследования стрикционного магнитоэлектрического эффекта в латерально-ограниченных магнитных частицах на поверхности сегнетоэлектриков. Интересной представляется возможность переключения магнитного состояния однородно намагниченных частиц между различными направлениями намагниченности, а также переключения между вихревыми и однородными состояниями и др.
Переключение между однородными состояниями с различным направлением намагниченности было продемонстрировано в работе [5]]. Однако, переключались отдельные случайные частицы и однородного переключения всех частиц не было получено. Для осуществления более контролируемого переключения магнитных частиц требуются дополнительные исследования в данной области. Так же был продемонстрирован магнитоупругий эффект в квадратных микрочастицах пермаллоя [6] и Со [7].

В нашей работе мы исследовали переключение субмикронных магнитных частиц $\mathrm{Ni}$ различной формы за счет магнитострикции. Нами не были использованы сегнетоэлектрические подложки. Вместо этого частицы изготавливались на стекле, которое механически изгибалось. Мы продемонстрировали, переключение при изгибе из вихревого в квазиоднородное магнитное состояние в таких частицах.

\section{2. Образцы и методика измерений}

Методами литографии и ионного травления были изготовлены частицы Ni различной формы (квадратные и эллиптические) на поверхности стеклянной пластины (рис. 1). Толщина исследованных частиц составляла $30 \mathrm{~nm}$. Размеры частиц варьировались от одного микрона до двухсот $\mathrm{nm}$ (рис. 2). Исследование зависимости магнитного состояния от деформаций проводилось методами магнитно-силовой микроскопии.

Особенностью наших измерений является использование устройства для контролируемого изгиба подложки (см. рис. 1) непосредственно в магнитно-силовом микроскопе. Измерения проводились при максимально возможном изгибе, определяющимся пределом упругой деформации подложки. 


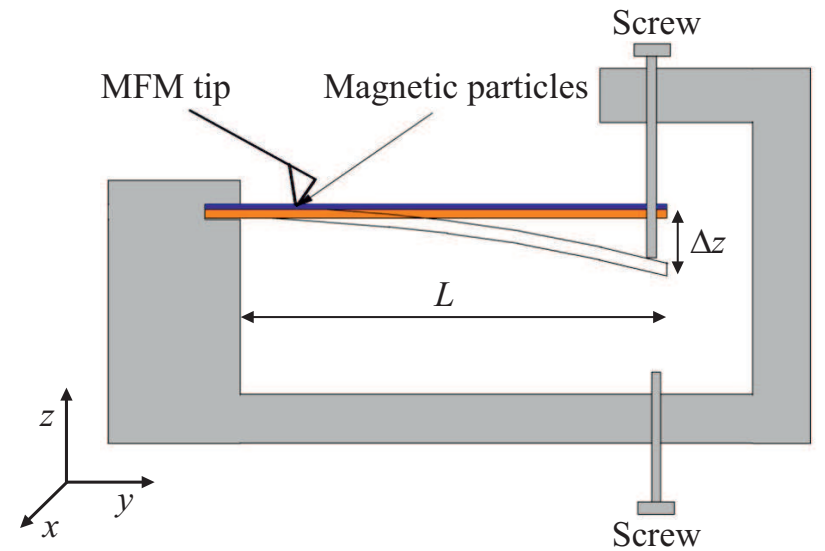

Pис. 1. Схема измерений зависимости свойств магнитных частиц от их деформации с помощью магнитно-силового микроскопа.

Для анализа полученных результатов было проведено микромагнитное моделирование в программе OOMMF [8]. Влияние деформаций моделировалось добавочной одноосной анизотропией $\left(K=8 \cdot 10^{3} \mathrm{~J} / \mathrm{m}^{3}\right)$ в плоскости магнитной пленки. Оценка величины наведенной анизотропии получена на основе данных об изгибе подложки (приводящей к деформациям порядка $0.2 \%$ ) и литературным данным о константе магнитострикции $\mathrm{Ni}$. Такая анизотропия возникает в пленках Ni вдоль оси однородного одноосного сжатия или перпендикулярно оси растяжения при сгибании подложки, на которой находятся магнитные частицы.

\section{3. Результаты}

Было экспериментально продемонстрировано, что изгиб подложки и связанное с ним растяжение или сжатие частиц Ni заметно влияет на их магнитное состояние.

В квадратных частицах с латеральными размерами от $1 \mu \mathrm{m}$ до $400 \mathrm{~nm}$ в начальном недеформированном состоянии в частицах наблюдалось квази-вихревое распределение намагниченности. На рис. 3 приведено МСМ изображение массива квадратных частиц (рис. 3,a), а так же полученное в программе ООММF распределение намагниченности в таких частицах (рис. 3,b) и рассчитанное на его основе модельное МСМ изображение (рис, 3,c).

При изгибе подложки деформации приводят к возникновению наведенной анизотропии, с осью, направленной вдоль оси растяжения или поперек направления сжатия (на рисунках ось анизотропии отмечена белой стрелкой). Это в свою очередь приводит к изменению магнитного состояния в частицах. Область доменов, намагниченных вдоль оси анизотропии, увеличивается, а область доменов, намагниченных поперек - уменьшается. На рис. 4 представлен массив частиц, на подложке, растянутой вдоль оси $y$. То есть ось наведенной анизотропии направлена вдоль оси $x$. Красной рамкой на рис. 3,4 и 5 выделен совпадающий на всех кадрах участок массива. Как видно из МСМ изображения, растяжение подложки приводит к переходу части частиц в квазиоднодоменное состояние, показанное на рис. 4. Частицы, перешедшие в однодоменное состояние, выделены белой рамкой. Еще некоторое колличество частиц переходит в двухдоменное состояние (выделены синей рамкой), о котором будет подробнее рассказано ниже. Переход в то или иное состояние, определяется несовершенствами формы магнитных частиц.

Моделирование показывает, что в квадратных частицах с наведенной деформациями анизотропией имеется два метастабильных состояния с двухдоменным и квазиоднородным распределением намагниченности. Такие состояния и наблюдаются в нашем эксперименте.

При сжатии подложки вдоль оси $y$ ось наведенной анизотропии направлена вдоль оси $y$. Как показано на рис. 5, большинство частиц переходят из вихревого состояния в двухдоменное за счет увеличения площади доменов, намагниченность которых направлена вдоль оси наведенной анизотропии. Интересно отметить, что
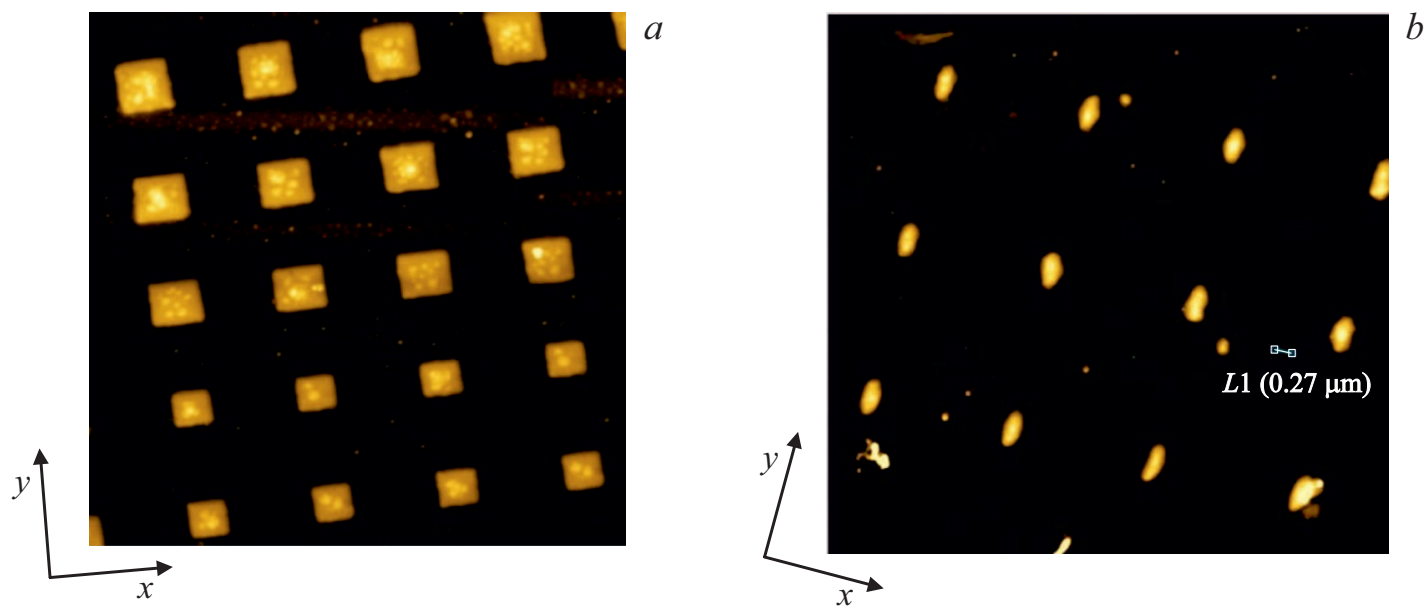

Рис. 2. АСМ изображение участка массива (a) квадратных частиц Ni. (b) эллиптических частиц Ni. Размер кадра $8 \mu \mathrm{m}$. 
$a$

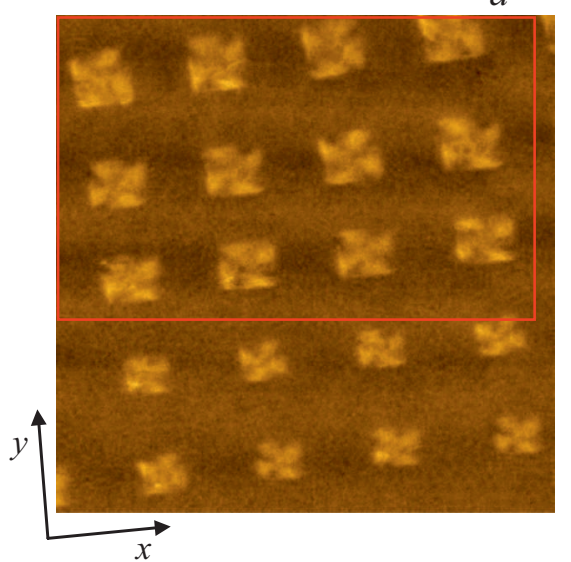

$b$

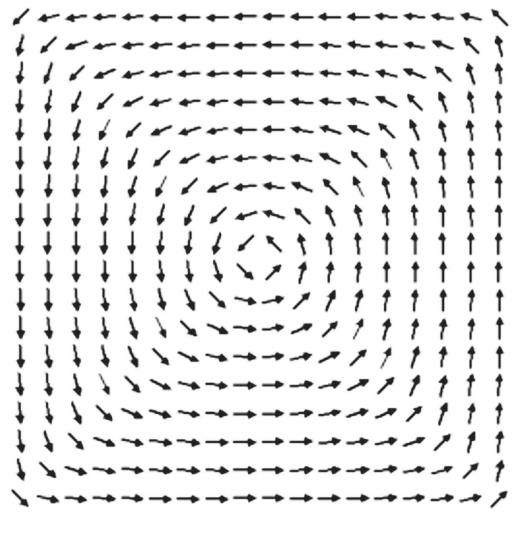

C

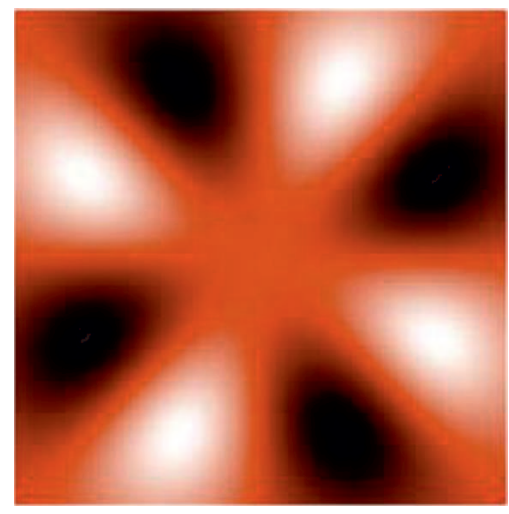

Рис. 3. (a) МСM изображение участка массива квадратных частиц Ni в невозмущенном состоянии (a). Размер кадра $8 \mu \mathrm{m}$. (b) модельное вихревое распределение намагниченности в квадратной частицеи соответствующее ему модельное МСМ изображение $(c)$.
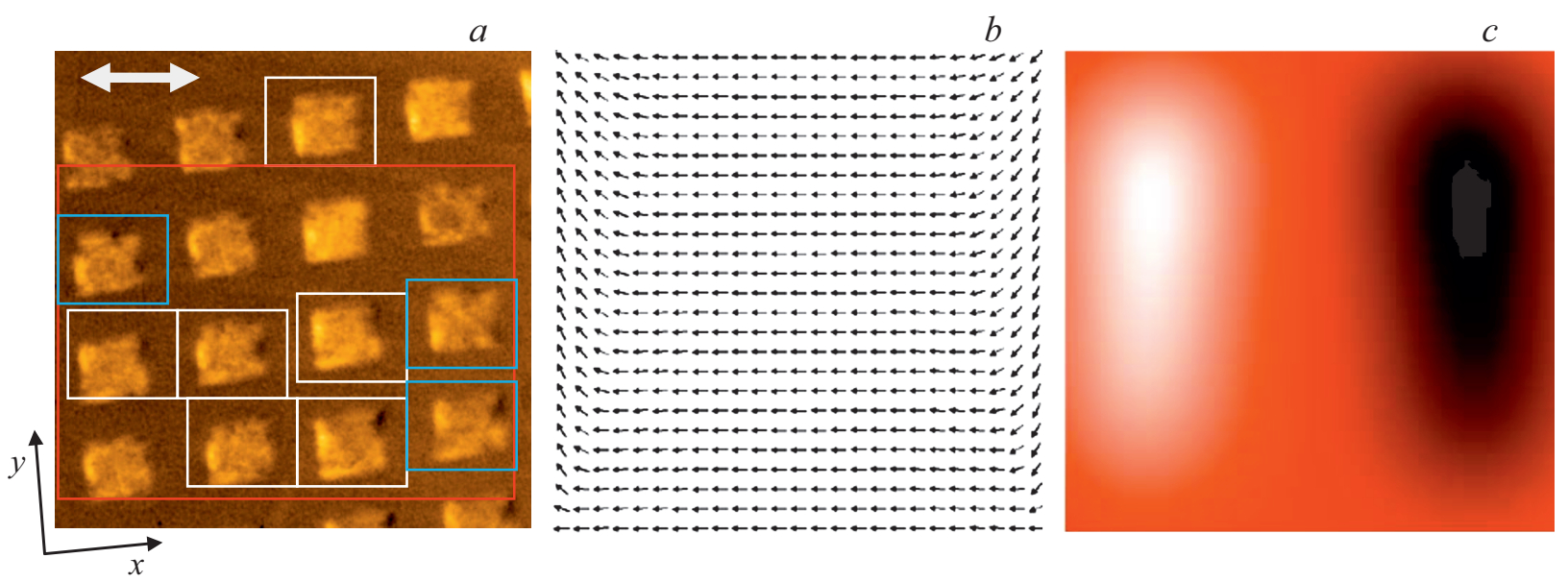

Рис. 4. (a) МСМ изображение участка массива квадратных частиц Ni при растяжении подложки вдоль оси $y$. Размер кадра $8 \mu$ m. (b) модельное квазиоднородное распределение намагниченности в квадратной частице и соответствующее ему модельное МСМ изображение $(c)$.
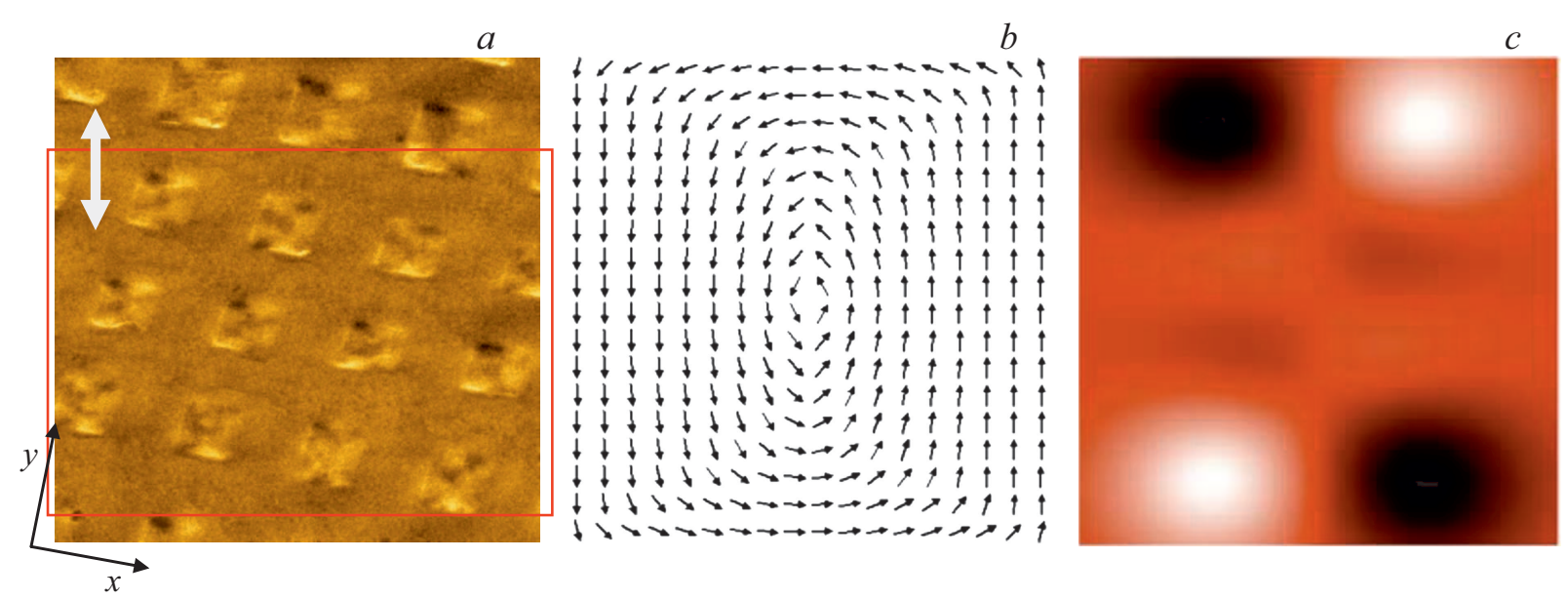

Pис. 5. (a) МСМ изображение участка массива квадратных частиц Ni при сжатии подложки вдоль оси $y$. Размер кадра $8 \mu$ m. (b) модельное двухдоменное распределение намагниченности в квадратной частице и соответствующее ему модельное МСМ изображение $(c)$. 

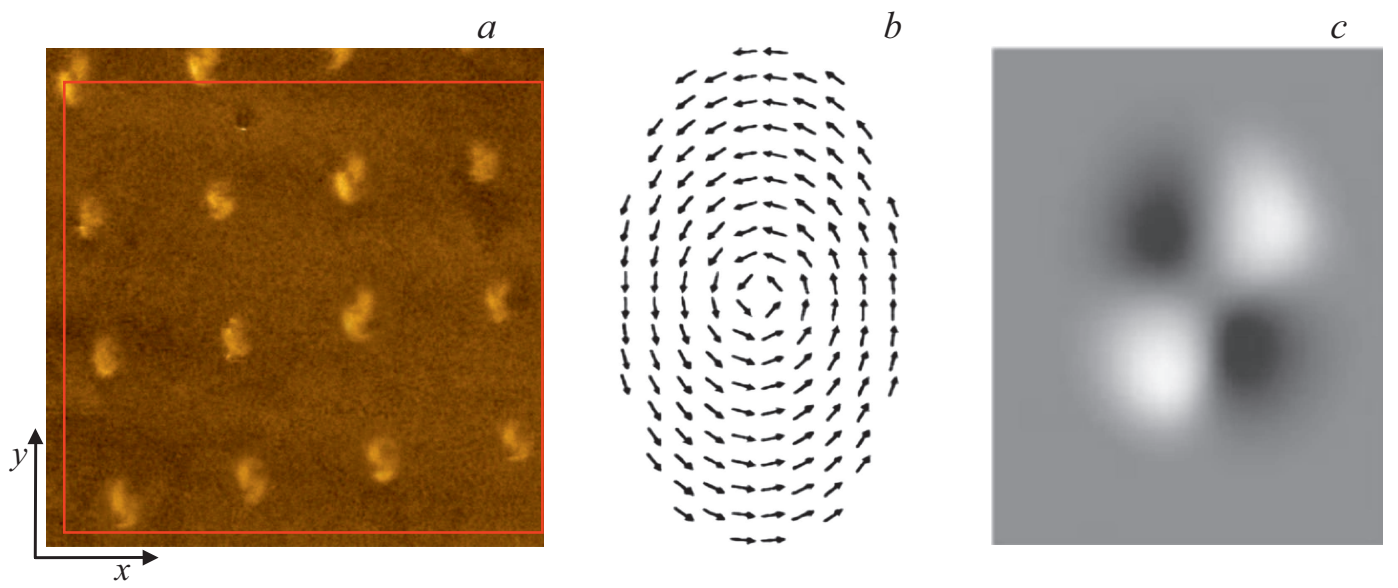

Рис. 6. (a) МСM изображение участка массива эллиптических частиц Ni в невозмущенном состоянии. Размер кадра $8 \mu$ m. (b) модельное вихревое распределение намагниченности в эллиптической частице и соответствующее ему модельное МСМ изображение $(c)$.

$a$

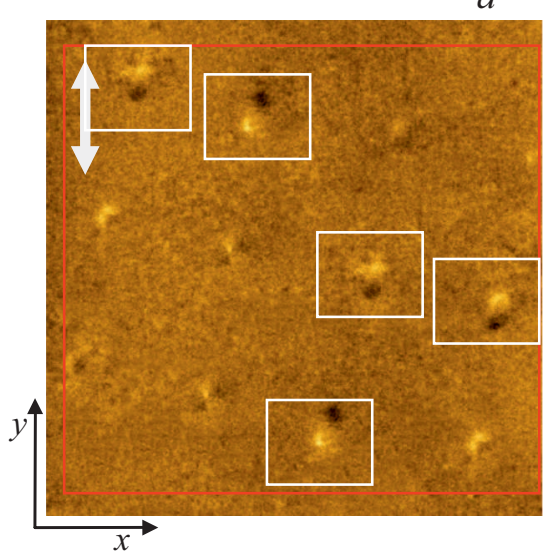

$b$

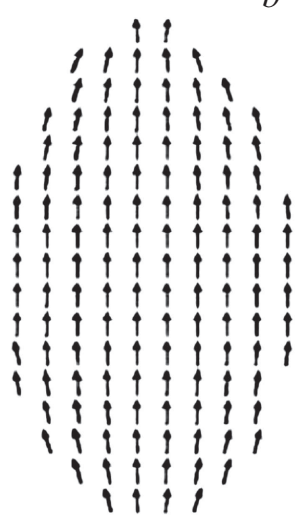

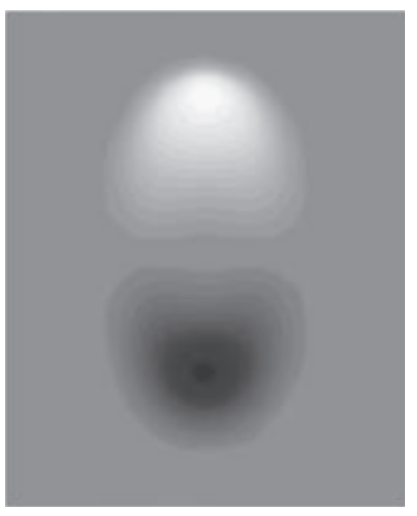

Рис. 7. (a) MCM изображение участка массива эллиптических частиц Ni в невозмущенном состоянии. Размер кадра $8 \mu \mathrm{m}$. (b) модельное вихревое распределение намагниченности в эллиптической частице и соответствующее ему модельное МСМ изображение $(c)$.

при создании деформаций сжатия вдоль оси $y$, не возникает частиц с квазиоднородным распределением намагниченности, как это было при деформациях растяжения. Это может быть связано с тремя факторами: 1) величина деформации при сжатии и растяжении не одинакова, что связано с несимметричностью устройства зажима подложки (данную асимметрию мы наблюдали, используя тензодатчик, приклеенный к подложке). Величины деформаций при сжатии может быть недостаточно для перехода в однородное состояние; 2) форма частиц может быть слегка вытянутой вдоль оси $x$. Это помогает в формировании однодоменного состояния; 3) существует ось анизотропии в магнитной пленке, из которой изготовлены магнитный частицы. Данная ось анизотропии может способствовать возникновению однородного состояния вдоль оси $x$ и препятствовать возникновению такого состояния вдоль оси $y$.
Так же было исследовано перемагничивание эллиптических частиц размером 400 на $200 \mathrm{~nm}$. В недеформированном состоянии в частицах реализовывается вихревое распределение намагниченности (рис. 6). Как известно, магнитное состояние в таких частицах определяется конкуренцией обменной и магнитостатической энергий. При приложении механического напряжения дополнительно возникает одноосная анизотропия, способствующая формированию однодоменного состояния.

При растяжении образца в том же направлении, ось наведенной анизотропии будет направлена вдоль короткой оси частиц. В этом случае, величина наведенной анизотропии оказалась недостаточной, и перехода частиц в однородное состояние не наблюдалось.

Подобный эффект переключения из вихревого в однородное состояние наблюдался только для частиц размером 200 на $400 \mathrm{~nm}$. Для частиц большего размера переключение не наблюдалось. Очевидно, это 
связано с тем, что при увеличении размера частиц, вихревое состояние становится все более энергетически выгодным по сравнению с однородным и величины наведенной анизотропии не хватает для перемагничивания.

\section{4. Заключение}

Таким образом, в настоящей работе была экспериментально продемонстрирована возможность управления магнитным состоянием микрочастиц $\mathrm{Ni}$ при помощи их деформации. Были изготовлены и исследованы массивы частиц квадратной и эллиптической форм. Было показано, что для квадратных частиц деформация как сжатия так и растяжения приводит к изменению магнитного состояния частиц. При растяжении частицы переходят в однородное магнитное состояние, а при сжатии в двухдоменное. Для эллиптических частиц изменение магнитного состояния наблюдается только при сжатии их вдоль длинной оси. При этом происходит переход из вихревого состояния в однородное.

\section{Финансирование работы}

Моделирование магнитных частиц, а также магнитносиловые исследования выполнены при поддержке Российского научного фонда (грант номер 18-72-10026). Изготовление магнитных частиц выполнено при поддержке гранта РФФИ 18-42-520013.

\section{Конфликт интересов}

Авторы заявляют, что у них нет конфликта интересов.

\section{Список литературы}

[1] Greg P. Carman. IEEE Traycact. Magn. 51, 12, 0600104 (2015)

[2] M. Fiebig. J. Phys. D 38, R123 (2005).

[3] S. Fusil, V. Garcia, A. Barthelemy, M. Bibes. Ann. Rev. Mater. Res. 44, 91 (2014).

[4] А.А. Бухараев, А.К. Звездин, А.П. Пятаков, Ю.К. Фетисов, УФН, 188, 12, 1288 (2018).

[5] M. Buzzi, R.V. Chopdekar, J.L. Hockel, A. Bur, T. Wu, N. Pilet, P. Warnicke, G.P. Carman, L.J. Heyderman, F. Nolting, Phys. Rev. Lett. 111, 027204 (2013).

[6] Д.А. Бизяев, А.А. Бухараев, Ю.Е. Кандрашкин, Л.В. Мингалиева, Н.И. Нургазизов, Т.Ф. Ханипов. Письма в ЖТФ 42, 20, 24 (2016).

[7] S. Finizio, M. Foerster, M. Buzzi, B. Krüger, M. Jourdan, C.A.F. Vaz, J. Hockel, T. Miyawaki, A. Tkach, S. Valencia, F. Kronast, G.P. Carman, F. Nolting, M. Kläui. Phys. Rev. Appl. 1, 021001 (2014).

[8] M.J. Donahue, D.G. Porter. „OOMMF User's Guide“, Interagency Report NISTIR 6376, National Institute of Standards and Technology, Gaithersburg, MD (1999). http://math.nist.gov/oommf

Редактор Т.Н. Василевская 